\title{
Microwave-Regenerated Diesel Exhaust Particulate Filter
}

\author{
Richard D. Nixdorf \\ Industrial Ceramic Solutions, LLC \\ Johney B. Green Jr., John M. Story and Robert M. Wagner \\ Oak Ridge National Laboratory
}

Reprinted From: Diesel Exhaust Emission Control: Diesel Particulate Filters

(SP-1582) 
The appearance of this ISSN code at the bottom of this page indicates SAE's consent that copies of the paper may be made for personal or internal use of specific clients. This consent is given on the condition, however, that the copier pay a $\$ 7.00$ per article copy fee through the Copyright Clearance Center, Inc. Operations Center, 222 Rosewood Drive, Danvers, MA 01923 for copying beyond that permitted by Sections 107 or 108 of the U.S. Copyright Law. This consent does not extend to other kinds of copying such as copying for general distribution, for advertising or promotional purposes, for creating new collective works, or for resale.

SAE routinely stocks printed papers for a period of three years following date of publication. Direct your orders to SAE Customer Sales and Satisfaction Department.

Quantity reprint rates can be obtained from the Customer Sales and Satisfaction Department.

To request permission to reprint a technical paper or permission to use copyrighted SAE publications in other works, contact the SAE Publications Group.

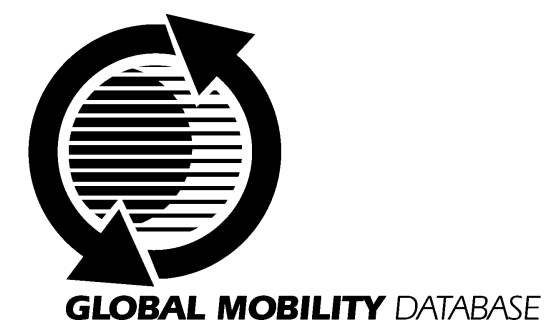

All SAE papers, standards, and selected books are abstracted and indexed in the Global Mobility Database

No part of this publication may be reproduced in any form, in an electronic retrieval system or otherwise, without the prior written permission of the publisher.

ISSN 0148-7191

Copyright 2001 Society of Automotive Engineers, Inc.

Positions and opinions advanced in this paper are those of the author(s) and not necessarily those of SAE. The author is solely responsible for the content of the paper. A process is available by which discussions will be printed with the paper if it is published in SAE Transactions. For permission to publish this paper in full or in part, contact the SAE Publications Group.

Persons wishing to submit papers to be considered for presentation or publication through SAE should send the manuscript or a 300 word abstract of a proposed manuscript to: Secretary, Engineering Meetings Board, SAE.

\section{Printed in USA}




\title{
Microwave-Regenerated Diesel Exhaust Particulate Filter
}

\author{
Richard D. Nixdorf \\ Industrial Ceramic Solutions, LLC \\ Johney B. Green Jr., John M. Story and Robert M. Wagner \\ Oak Ridge National Laboratory
}

Copyright @ 2001 Society of Automotive Engineers, Inc.

\begin{abstract}
Development of a microwave-regenerated particulate filter system has evolved from bench scale work to actual diesel engine experimentation. The filter system was initially evaluated on a stationary mounted 1.2-L diesel engine and was able to remove a significant amount of carbon particles from the exhaust. The ability of the microwave energy to regenerate or clean the filter was also demonstrated on this engine under idle conditions. Based on the 1.2- $\mathrm{L}$ experiments, improvements to the filter design and materials were implemented and the system was re-evaluated on a vehicle equipped with a 7.3- $\mathrm{L}$ diesel engine. The 7.3- $\mathrm{L}$ engine was selected to achieve heavy filter loading in a relatively short period of time. The purpose of these experiments was to evaluate filter-loading capacity, power requirements for regeneration, and filter regeneration efficiency. A more detailed evaluation of the filter was performed on a stationary mounted 1.9-L diesel engine. The effect of exhaust flow rate, loading, transients, and regeneration on filter efficiency was evaluated with this setup. In addition, gaseous exhaust emissions were investigated with and without an oxidation catalyst on the filter cartridge during loading and regeneration.
\end{abstract}

\section{INTRODUCTION}

Compliance with the final phases of the proposed diesel engine exhaust emissions standards for North America, Europe, and Japan will probably require some form of a carbon particulate filter. Since the mid-1980's, engine manufacturer's have investigated devices to physically filter or trap particulates on the walls of a wall-flow honeycomb ceramic extrusion. The exhaust gases are forced to flow through the monolith wall and exit the adjoining channel. Other devices incorporate metal mesh, wound ceramic fibers and ceramic foam structures. Each of these devices has a limited capacity to trap carbon particles before backpressure drop becomes excessive. Some form of thermal energy must be applied to the filter to combust the carbon particles and clean the filter. Carbon particles can be removed in the range of $400-450{ }^{\circ} \mathrm{C}$ [1]. This combustion temperature may be reduced by approximately $100^{\circ} \mathrm{C}$, with the addition of a precious metal catalyst to the filter cartridge.

Small diesel engines, such as those used in automobiles, are commonly operated under low load conditions where the exhaust temperature is below that required for carbon combustion. An external heating source is required to achieve reliable particulate filter regeneration or cleaning. Electrical resistance, fuel burners, or engine controls have been used to apply the auxiliary heat to increase the exhaust temperature. Microwave power has been used to heat trapped carbon particles but problems arose due to unpredictable carbon deposition on the filter and uneven microwave heating [2]. A unique silicon carbide fiber has been discovered that converts microwave energy to heat energy with nearly $100 \%$ efficiency. These special fibers initiated the development of a microwave regenerated particulate filter system that heats uniformly, regardless of the carbon deposit distribution or quantity. The microwaves heat the evenly dispersed silicon carbide fibers to the carbon combustion temperature.

A filter cartridge (Figure1) made of these fibers can be heated to $800^{\circ} \mathrm{C}$ in a microwave field in approximately three minutes (Figure 2). The conversion to heat is most efficient at the $2.45 \mathrm{GHz}$ microwave frequency used in hundreds of millions of microwave heating appliances. The ability to use the same microwave electronics as high-volume commercial microwave ovens reduces the cost of the power source to heat fiber filter shapes. 


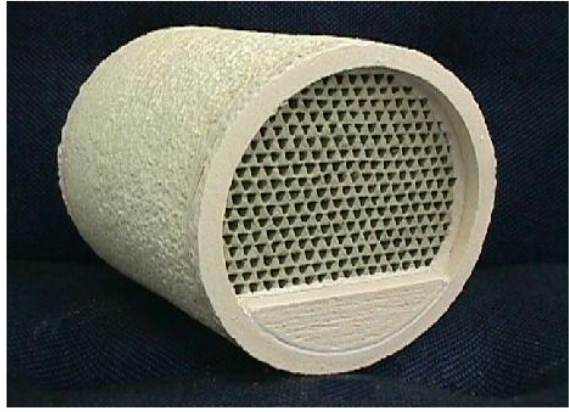

Figure 1. Wall-flow design filter cartridge $12.7 \mathrm{~cm}$ in diameter $\times 12.7 \mathrm{~cm}$ in length

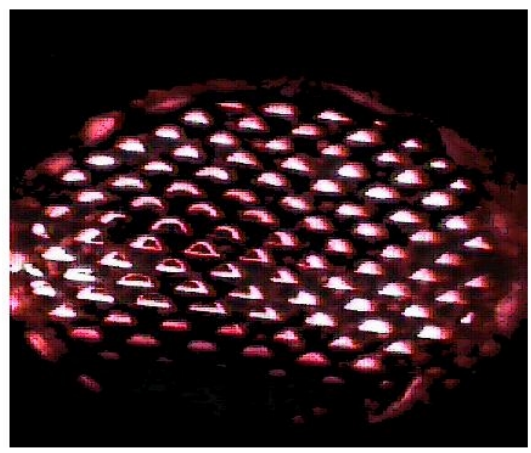

Figure 2.

$12.7 \mathrm{~cm}$ silicon carbide fiber cartridge exposed to one $\mathrm{KW}$ microwave power

The relatively large size of the silicon carbide fiber, 0.016 microns in diameter $\times 0.500$ microns long, allows its conversion to a durable ceramic paper using standard commercial papermaking equipment. Improvements in the strength and porosity of the ceramic paper media have been developed, with the aid of modern ceramic technology. This improved ceramic paper is fabricated into durable filter shapes that efficiently remove fine particulate from high-velocity exhaust streams. The ceramic filter cartridge, incorporating the silicon carbide paper media, traps diesel exhaust soot. When the filter reaches its designed capacity for carbon particulate, the microwave power is activated for the time period required to reach the particulate destruction temperature. The silicon carbide fiber filter reacts with the microwave energy to rapidly combust the pollutants to harmless carbon dioxide and water. A schematic diagram of the microwave regenerated filter system is shown in Figure 3.

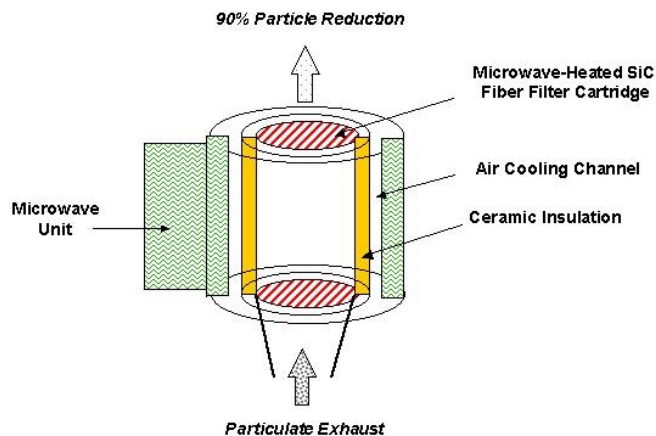

Figure 3. Microwave-Regenerated Particulate Filter System

\section{EXPERIMENTAL WORK AND RESULTS}

\section{ENGINE EXHAUST TESTING EXPERIMENTAL}

DETAILS - In previous evaluations of other microwaveregenerated filter devices, the cleaning cycle was applied while the exhaust was bypassed around the filter [3]. Practical application requires the filter cartridge cleaning cycle to be performed under realistic engine operating conditions without a bypass valve system. Therefore in these experiments, the microwave cleaning cycle was always conducted at idle conditions for all engines. The filter was loaded at various steady state and transient cycle conditions, and then engine conditions were changed to idle for the five-minute microwave cleaning sequence. Subsequent testing indicates that a 2-minute microwave cycle may be sufficient. Particulate filter performance was evaluated on three diesel engines. A 1.2-L, four cylinder DIATA CIDI engine was used to measure the silicon carbide fiber filter's particulate removal efficiency and to establish a protocol for microwave cleaning of the filter. A 7.3-L, eight-cylinder CIDI engine mounted in a vehicle provided a high sootloading source to evaluate many consecutive microwave cartridge-cleaning efficiencies. Combustion of heavy carbon loadings has resulted in cracking and melting in many types of filter cartridges. Therefore, this was considered a fair test of the durability of the fiber paper ceramic cartridge. The third group of experiments, conducted on a 1.9-L, 4- cylinder CIDI engine, examined the filter particulate removal efficiency at steady state and transient cycle conditions, the particle size of the material passing through the filter, and the emissions produced during microwave regeneration.

Filter Cartridge and Microwave Hardware Details Testing of microwave dielectric properties showed that a 25 wt. \% silicon carbide fiber, 75 wt. \% alumina-silicate fiber filter media paper would evenly absorb the 2.45 $\mathrm{GHz}$ microwave field from the exterior to the center of the filter cartridge. This paper was fabricated to a thickness of one millimeter with an average open porosity of 25 micrometers. The paper was corrugated 
and formed into a cylindrical wall-flow type filter cartridge, with opposite $5 \times 5$ millimeter channels blocked. The filter cartridge dimensions are 12.7 centimeters in diameter $x 12.7$ centimeters in length; cartridge volume is 1.6 liters, and the filter media area is 0.232 square meters. The filter cartridge, shown in Figure 1, was contained in a 1.25-centimeter thick oxide fiber insulation wrap.

The filter cartridge can assembly was a stainless steel cylinder, which served as the microwave applicator, as shown in Figure 4. Conical stainless steel transitions connect to the exhaust pipe. The microwaves were fed into the applicator by a rectangular aluminum waveguide. Microwave energy was generated and supplied to the waveguide by a 3-kilowatt magnetron.

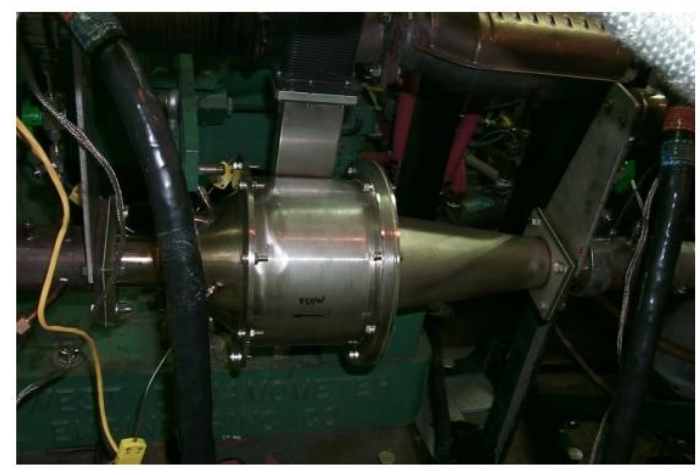

Figure 4. Canned filter cartridge mounted on 1.9-L Volkswagen TDI exhaust

1.2-L Ford DIATA CIDI Engine Setup - The microwave filter cartridge was evaluated in one hour cycles at three different engine speeds and loads: $1550 \mathrm{rpm}$ at $2.6 \mathrm{bar}$ BMEP, $2300 \mathrm{rpm}$ at 3.7 bar BMEP, and $2600 \mathrm{rpm}$ at 3.8 bar BMEP. At the end of each one-hour cycle the engine speed was reduced to $1000 \mathrm{rpm}$ and 1.7 kilowatts of microwave regeneration power was transferred to the filter cartridge for a period of five minutes. Carbon mass was measured before and after the particulate filter by an R\&P Tapered Element Oscillating Microbalance (TEOM) Model 1105. Pressure drop across the filter and temperature before and after the filter were measured. The fuel used for this experiment was Fischer Tropsch 100.

7.3-L Ford CIDI Chassis Dynamometer Setup - The microwave particulate filter was mounted on an external assembly at the rear of the truck as shown in Figure 5. The engine was operated under various conditions to determine the maximum soot production. Significant visible exhaust smoke was observed at $1250 \mathrm{rpm}$ in $5^{\text {th }}$ gear with a 450-kilogram load on the truck. Pressure and temperature were measured before and after the particulate filter. Six consecutive filter loading cycles were run at the visible smoke operating condition. During each cycle the filter was loaded from 5 to $20 \mathrm{kPa}$ of backpressure using 100 kilograms/hour of exhaust flow. Upon reaching $20 \mathrm{kPa}$ of backpressure, the exhaust flow was reduced to 12 kilograms/hour and the filter was exposed to 1.7 kilowatts of microwave power for regeneration. The filter was weighed, under controlled conditions, before and after each cycle to determine the quantity of deposited carbon. Regeneration efficiency was calculated using the measured pressure drop recovery after each microwave cleaning cycle. The fuel used for this experiment was a standard commercial \#2 diesel.

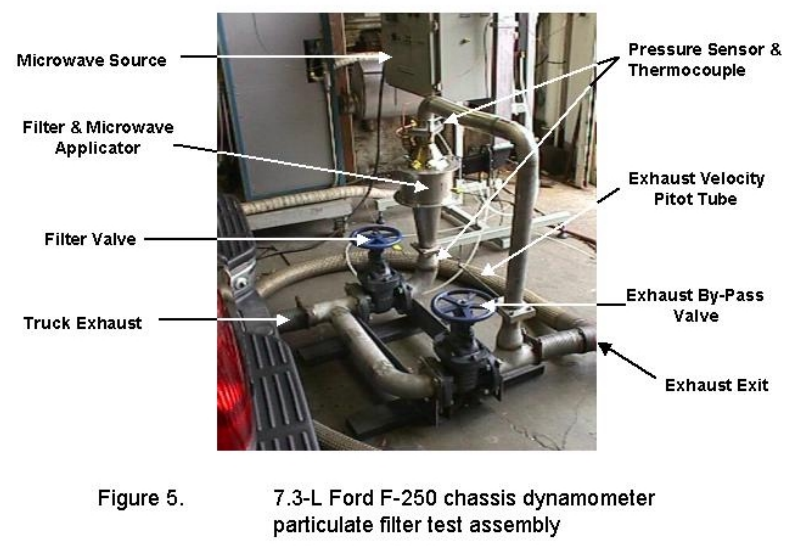

1.9-L VW TDI Engine Setup - The effect of exhaust flow rate, loading, transients, and regeneration on filter efficiency was evaluated on a 1997 1.9-L VW turbocharged, direct injection engine. Exhaust flow was controlled with a bypass flow system that allowed a fraction of the exhaust to be diverted around the filter. Additional equipment included a 4 inch mini-dilution tunnel, heated $\mathrm{NO}_{x}$ and $\mathrm{HC}$ analyzers, unheated $\mathrm{CO}$, $\mathrm{CO}_{2}$ and $\mathrm{O}_{2}$ analyzers, a TSI Scanning Mobility Particle Sizer (SMPS), and a TEOM Model 1105. The microwave particulate filter was installed approximately two meters from the exhaust manifold as shown in Figure 6 . The steady state experiments were performed at $1500 \mathrm{rpm}$ (2.6 bar BMEP) and $2300 \mathrm{rpm}$ (4.2 bar BMEP). An exhaust flow sweep was conducted for space velocities ranging from 10,000 to $70,000 \mathrm{hr}^{-1}$ at increments of $10,000 \mathrm{hr}^{-1}$. Emissions were investigated through repeated transient cycles with engine speeds ranging from idle to $2300 \mathrm{rpm}$. Exhaust emissions were recorded before and after the filter during the regeneration cycle. Near the end of this evaluation, a new filter cartridge, which was identical to the original except for the application of a precious metal catalyst, was installed in the system and briefly evaluated. The fuel used for this experiment was CARB specification reformulated diesel fuel. 


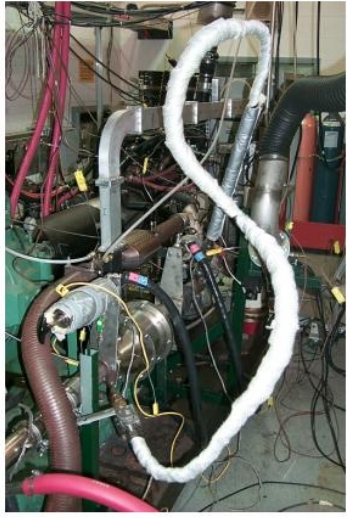

Figure 6.

1.9-L Volkswagen TDI stationery engine filter test assembly

\section{RESULTS AND DISCUSSIONS}

1.2-L DIATA Experiments - All previous development work on the silicon carbide fiber microwave regenerated particulate filter had been directed toward materials research, filter cartridge fabrication development, and understanding the microwave heating properties. This experiment was the first exposure of the system to filtration in a diesel exhaust stream and to microwave regeneration of a carbon impregnated filter. Particulate removal efficiency of the filter system during the three engine test conditions is shown in Figure 7.

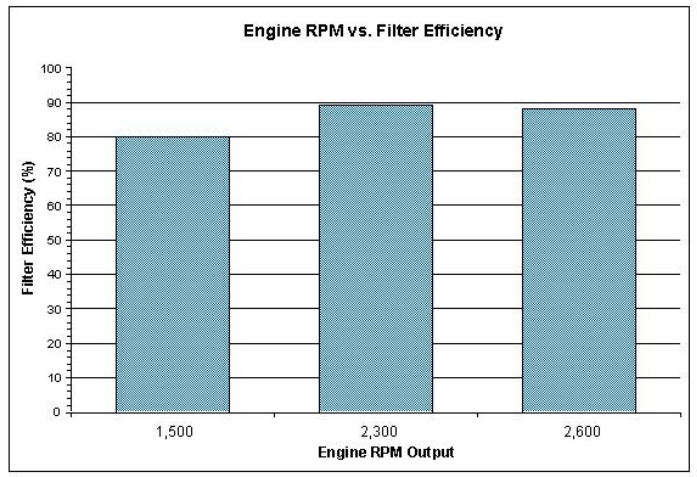

Figure 7. 1.2-L DIATA ceramic filter particulate removal efficiency

A typical regeneration cycle profile, using 1.7 kilowatts of microwave power for five minutes is displayed on the actual test cell data log plot in Figure 8.

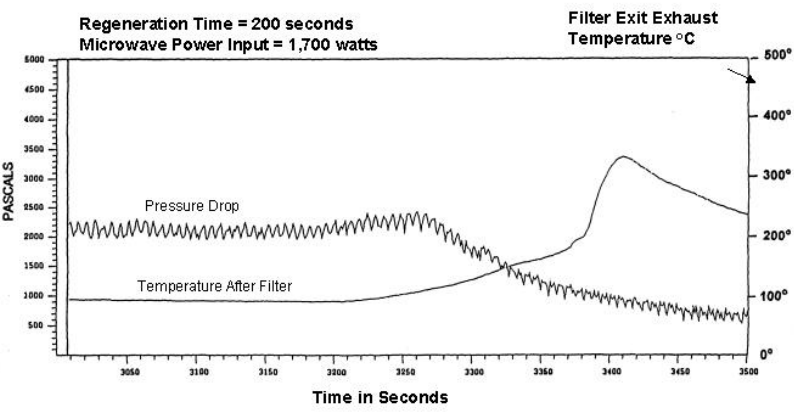

Figure 8. 1.2-L DIATA regeneration cycle at 1,000 RPM

Figure 9 shows the backpressure across the filter for the entire experimental sequence. It is obvious that the Fischer Tropsch fuel was depositing such a minute amount of carbon on the filter in the short one hour loading cycles that regeneration efficiency calculations would have little meaning.

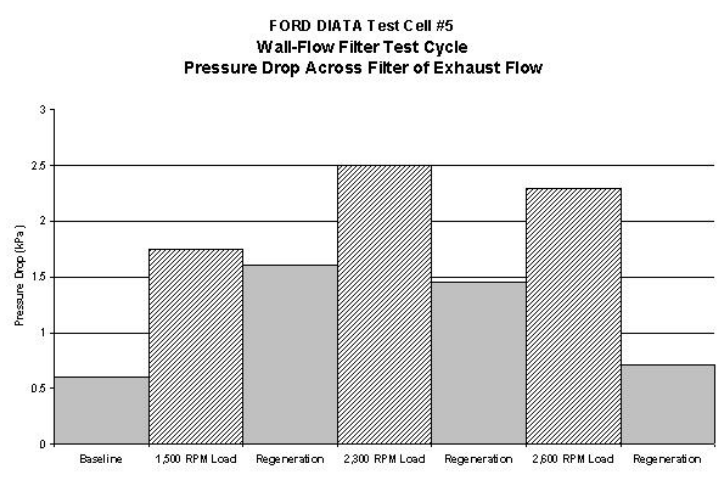

Figure 9. 1.2-L DIATA filter pressure drop changes across the filter during particulate loading and microwave regeneration

Several undesirable issues were encountered in this first test of the new technology. A substantial increase in carbon deposits on the filter was necessary to make microwave regeneration realistic and efficient. Secondly, the microwave field was concentrating at the entry port of the waveguide into the filter cartridge. Geometry changes were needed to improve microwave distribution within the filter cartridge. Finally, exhaust flow through the filter was concentrating at the center of the cartridge. A design change to improve the uniformity of the exhaust flow face-velocity across the filter was needed. All of these issues were addressed before moving into the next phase of engine experiments.

7.3-L Chassis Experiments - The filter particulate loading and microwave regeneration performance is shown in the filter backpressure chart in Figure 10. 


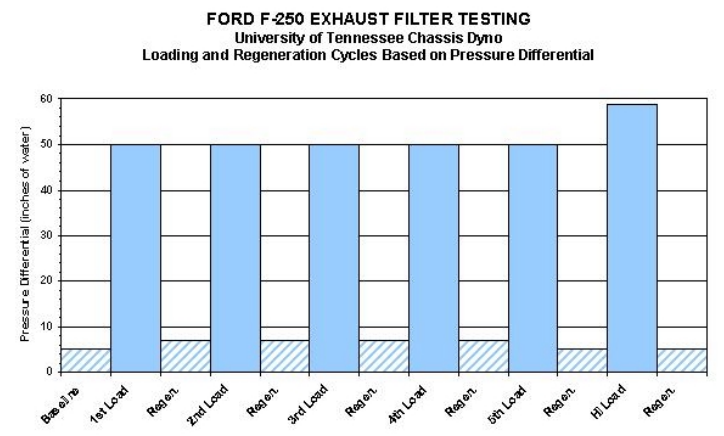

Figure 10. Microwave regeneration performance on sequential soot loading of the 7.3-L diesel exhaust

The quantity of carbon deposited on the filter was increased by a factor of ten over the earlier DIATA test cell, as seen in the experimental data in Figure 11. Microwave regeneration achieved a consistent recovery to within $95 \%$ of the clean filter condition. Examination of the filter cartridge through the six consecutive high soot loadings showed no structural or heat damage due to the microwave combustion of heavy carbon deposits. The 1.7 kilowatts of microwave power application was reduced from five minutes to two minutes during this experiment. Some exhaust bypassed the filter cartridge, as evidenced by the carbon deposits on the white insulation wrap.

FILTER LOADING AND REGENERATION DATA

\begin{tabular}{|c|c|c|c|c|}
\hline $\begin{array}{c}\text { Six (6) } \\
\text { Load \& } \\
\text { Regen. } \\
\text { Cycles }\end{array}$ & $\begin{array}{c}\text { Soot Load } \\
\text { (grams) }\end{array}$ & $\begin{array}{c}\text { Load Time } \\
\text { (minutes) }\end{array}$ & $\begin{array}{c}\text { Regen. } \\
\text { Time } \\
\text { (seconds) }\end{array}$ & $\begin{array}{c}\text { Regen. } \\
\text { Efficiency } \\
(\%)\end{array}$ \\
\hline $1^{\text {st }}$ Load & ---- & 52 & 120 & 93 \\
\hline $2^{\text {nd }}$ Load & 1.61 & 35 & 120 & 93 \\
\hline $3^{\text {rd }}$ Load & 1.35 & 35 & 120 & 93 \\
\hline $4^{\text {th }}$ Load & 1.37 & 35 & 120 & 93 \\
\hline $5^{\text {th } L o a d ~}$ & 2.81 & 33 & 120 & 100 \\
\hline Hi Load & 2.89 & 75 & 120 & 100 \\
\hline
\end{tabular}

Filter Loaded to 50 inches of water $(20 \mathrm{kPa})$ at visible black smoke conditions

Figure 11. Experimental data from the 7.3-L chassis dynamometer particulate filtration

1.9-L Experiments - The microwave filter system was next evaluated on a Volkswagen 1.9-L TDI engine. PM removal efficiency for two steady state conditions and a range of exhaust flows is shown in Figure 12. The flow sweep was performed by maintaining engine conditions while bypassing part of the exhaust flow around the filter. The filter exhibited efficiencies ranging from $60-95 \%$. The $60 \%$ filter efficiencies were due to significant exhaust leakage around the filter element resulting from a faulty seal design. However, it is important to note that the PM removal efficiency remained constant for the range of exhaust flows.

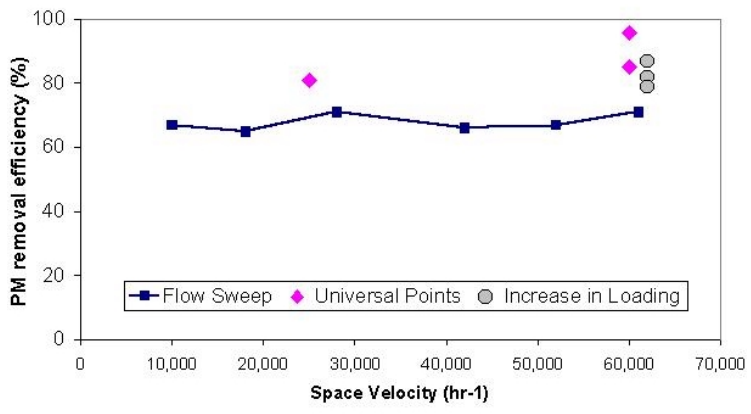
Figure 12. 1.9-L Volkswagen exhaust PM removal efficiency during
universal points and flow sweep engine operation

Figure 13 indicates the PM removal efficiency was approximately constant during transient engine cycles at engine speeds ranging from idle to $2300 \mathrm{rpm}$. In other words, the additional PM loading due to transient operation had no observable effect on filter efficiency. Particle size data were also acquired before and after the filter under steady state conditions. A representative sample of this data is shown in Figure 14. While the number concentrations are much smaller after the filter, the size distribution does not change noticeably. This indicates that all particles sizes are equally likely to be trapped in the filter.

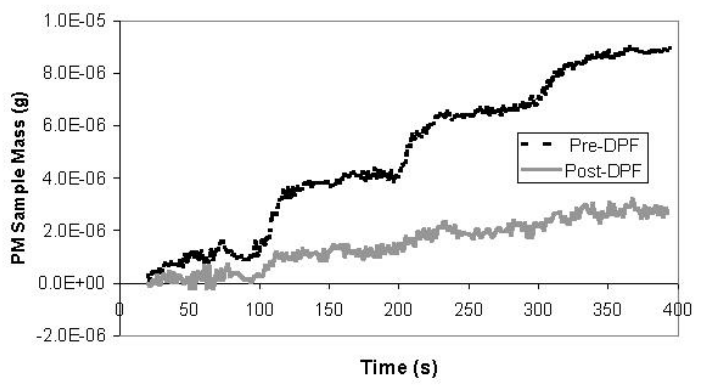

Figure 13. 1.9-L Volkswagen exhaust PM removal during transient engine cycles

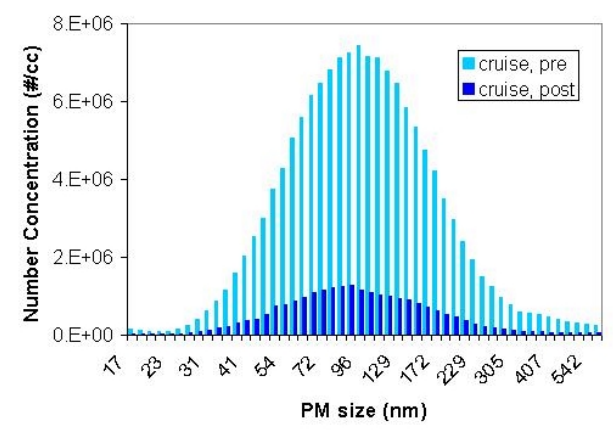

Figure 14. Particle size distribution of the carbon before and after the filter 
The filter was regenerated under low flow conditions by bypassing part of the exhaust flow. The initial exhaust temperature at the start of regeneration was $280^{\circ} \mathrm{C}$. As regeneration progressed, no adjustment was made to the bypass. This resulted in a higher exhaust flow at the end of the regeneration cycle due to the decrease in the pressure differential across the filter. Normalizing three different cases to one exhaust flow for comparison purposes developed Figure 15. When normalized to one flow, the PM emission rates out of the filter are nearly identical for loaded, clean, and regeneration conditions. The data in Figure 16 indicates a 30 second increase in hydrocarbon emissions during regeneration. The hydrocarbons are released during the rapid heating portion of the regeneration cycle. Similarly, CO increases dramatically during this period as combustion of the trapped PM occurs.

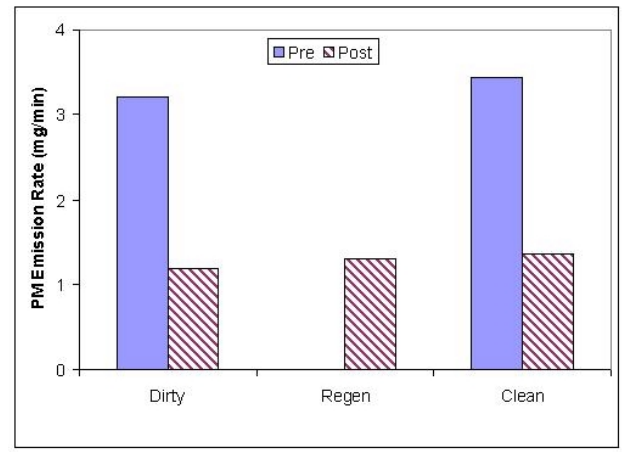

Figure 15. 1.9-L Volkswagen exhaust removal rate at steady-state operation during different filter conditions

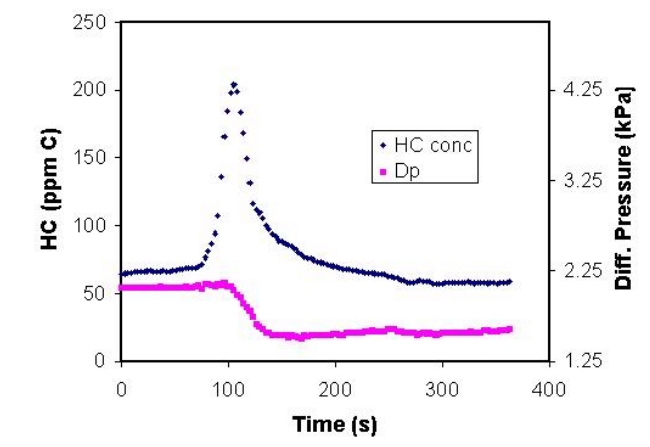

Figure 16. 1.9-L Volkswagen exhaust hydrocarbon emissions increase during microwave regeneration

A precious metal oxidation catalyst was applied to the silicon carbide fiber filter cartridge without a washcoat. Therefore, there was no change in the backpressure performance of the filter. On the 1.9-L engine at an operating speed of $1600 \mathrm{rpm}$, the filter exhibited a uniform $85 \%$ reduction in hydrocarbon emissions and an
$83 \%$ reduction in $\mathrm{CO}$ emissions for a 120 -minute period. After a microwave regeneration, the filter exhibited identical performance in $\mathrm{HC}$ and $\mathrm{CO}$ conversion at 2300 rpm for a similar time period.

Calculated Regeneration Frequency and Fuel Penalty for the 1.9-L Volkswagen - Regeneration frequency may be approximated using the carbon deposit weight of 2.81 grams to reach a $20 \mathrm{kPa}$ filter backpressure on the test filter cartridge during the 7.3-L engine testing. These weights can be combined with the exhaust particulate output of 0.019 grams/minute measured during the $1.9-\mathrm{L}$ engine testing, at a given engine load condition, such as $1600 \mathrm{rpm}$ at 123 newton-meters torque.

2.81 grams carbon $/ 0.019$ grams per minute $=148$ minutes (tested filter)

0.557 meter $^{2}$ pleated filter area/0.232 meter $^{2}$ wall-flow area $=2.4$ multiple of increased capacity for the pleated filter

2.4 multiple capacity increase $\times 148$ minutes $=355$ minutes $/ 60$ minutes per hour $=5.9$ hours between regenerations for a pleated filter configuration

\section{$\underline{\text { Regeneration would occur for } 2 \text { minutes every } 6 \text { hours }}$}

$1.7 \mathrm{KW} / 65 \%$ efficiency of microwave conversion $=2.6$ $\mathrm{KW}$ from the engine

2.6 $\mathrm{KW}$ for 2 minutes $/ 60$ minutes per hour $=0.087 \mathrm{KW}$ hours

$0.087 \mathrm{KW}$-hours / 6 hours between regenerations = $0.015 \mathrm{KW}$-hours per hour

Regeneration would require an average of 15 watts per hour from the engine

FUTURE WORK - The most obvious difficulty with the experimental results was the failure of the seals to contain the exhaust flow within the filter. Design changes will be implemented to address this issue. Microwave uniformity within the filter cartridge can be substantially improved with the use of microwave field finite element computer programs. Filter cartridge pressure drop, carbon particulate capacity, and time between microwave regenerations can be improved by moving from the inefficient wall-flow to a classic pleated filter configuration. The unusual strength of the ceramic paper media will allow this design change. These improvements will be tested on a stationary engine, and then moved onto a vehicle for on-road durability testing. 


\section{CONCLUSION}

PM emissions are one part of the pending standards for diesel engines. $\mathrm{NO}_{x}, \mathrm{HC}$ and $\mathrm{CO}$ are equally important. Catalyst driven solutions are being investigated for control of all emission species. These catalyst systems need high-load conditions (high exhaust temperatures) to operate. A low-load operating condition in smaller diesel engines is a significant percentage of the driving cycle. An active heating source will be needed in many applications. The silicon carbide fiber microwave regenerated diesel particulate filter has demonstrated, in its first trials on a diesel engine, an $80-95 \%$ PM removal efficiency and a $95 \%$ microwave cleaning efficiency. The microwave-regenerated filter PM removal efficiency is not affected by transient cycles or flow rates. The filter cartridge has the potential to combine passive catalyst filter regeneration at high loads with active microwave regeneration at low loads and idle conditions.

\section{ACKNOWLEDGEMENTS}

The authors acknowledge the support of the U. S. Department of Energy's Partnership for the New Generation Vehicle Program under the project direction of Ken Howden for funding this work. Gratitude is expressed to the Ford Motor Company and their employees Tim Gardener and Scott Low for donating test cell time and expertise. The microwave components were supplied by Hal Kimrey of Microwave Materials Technologies.

\section{REFERENCES}

1. Heck R.M. and Farrauto R.J., Catalytic Air Pollution Control. John Wiley \& Sons, Inc., 1995, p. 118

2. "Microwave Regenerated Filters", DeiselNet Technology Guide, www.dieselnet.com/tech/dpf microwave, Feb. 2000.

3. Guatam M., Popuri S., Rankin B. and Seehra M., "Development of a Microwave Assisted Regeneration System for a Ceramic Diesel Particulate System", SAE Paper SAE 1999-01-3565. 